\title{
Lessons learnt on recruitment and fieldwork from a pilot European human biomonitoring survey
}

Ulrike Fiddicke ${ }^{\mathrm{a}, *}$, Kerstin Becker ${ }^{\mathrm{a}}$, Gerda Schwedler ${ }^{\mathrm{a}}$, Margarete Seiwert ${ }^{\mathrm{a}}$, Reinhard Joas ${ }^{\mathrm{b}}$, Anke Joas ${ }^{\mathrm{b}}$, Pierre Biot ${ }^{\mathrm{c}}$, Dominique Aerts ${ }^{\mathrm{c}}$, Ludwine Casteleyn ${ }^{\mathrm{d}}$, Birgit Dumez $^{\mathrm{d}}$, Argelia Castaño ${ }^{\mathrm{e}}$, Marta Esteban ${ }^{\mathrm{e}}$, Jürgen Angerer ${ }^{\mathrm{f}}$, Holger M. Koch ${ }^{\mathrm{f}}$, Greet Schoeters $^{g}$, Elly Den Hond ${ }^{\mathrm{h}}$, Ovnair Sepai ${ }^{\mathrm{i}}$, Karen Exley ${ }^{\mathrm{i}}$, Lisbeth E. Knudsen ${ }^{\mathrm{j}}$, Milena Horvat ${ }^{\mathrm{k}}$, Louis Bloemen ${ }^{\mathrm{l}}$, Andromachi Katsonouri ${ }^{\mathrm{m}}$, Adamos Hadjipanayis ${ }^{\mathrm{n}}$, Milena Cerna ${ }^{\circ}$, Andrea Krsková ${ }^{p}$, Janne Fangel Jensen ${ }^{j}$, Jeanette K.S. Nielsen ${ }^{j}$, Peter Rudnai ${ }^{\mathrm{q}}$, Szilvia Közepésy ${ }^{\mathrm{q}}$, Arno C. Gutleb ${ }^{\mathrm{r}}$, Marc E. Fischer ${ }^{\mathrm{s}}$, Danuta Ligocka ${ }^{\mathrm{t}}$,

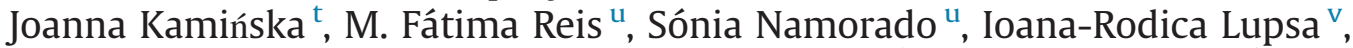
Anca E. Gurzau ${ }^{v}$, Katarína Halzlová ${ }^{w}$, Darja Mazej ${ }^{\mathrm{k}}$, Janja Snoj Tratnik ${ }^{\mathrm{k}}$, Teresa C. Rivas ${ }^{\mathrm{e}}$, Silvia Gómez ${ }^{\mathrm{e}}$, Marika Berglund ${ }^{\mathrm{x}}$, Kristin Larsson ${ }^{\mathrm{x}}$, Andrea Lehmann ${ }^{\mathrm{y}}$, Pierre Crettaz ${ }^{\mathrm{y}}$, Marie-Christine Dewolf ${ }^{z}$, Damien Burns ${ }^{\text {aa }}$, Anne Kellegher ${ }^{\text {ab }}$, Marike Kolossa-Gehring ${ }^{a}$

${ }^{a}$ Federal Environment Agency (UBA), Berlin, Germany

${ }^{\mathrm{b}}$ BiPRO GmbH, Munich, Germany

${ }^{\mathrm{c}}$ Federal Public Service Health, Food Chain Safety and Environment, Brussels, Belgium

${ }^{\mathrm{d}}$ University of Leuven, Leuven, Belgium

e Environmental Toxicology, Centro Nacional de Sanidad Ambiental (CNSA), Instituto de Salud Carlos III (ISCIII), Madrid, Spain

${ }_{\mathrm{f}}^{\mathrm{f}}$ Institute for Prevention and Occupational Medicine of the German Social Accident Insurance-Institute of the Ruhr University Bochum (IPA), Bochum, Germany

${ }^{\mathrm{g}}$ University of Antwerp, Belgium and Southern Denmark University, Denmark and Flemish Institute for Technological Research (VITO), Mol, Belgium

${ }^{\text {h }}$ Flemish Institute for Technological Research (VITO), Mol, Belgium

i Public Health England, Centre for Radiation, Chemical and Environmental Hazards, Oxfordshire, United Kingdom

j University of Copenhagen, Copenhagen, Denmark

k Jožef Stefan Institute, Ljubljana, Slovenia

${ }^{1}$ Environmental Health Science International, Hulst, The Netherlands

m State General Laboratory, Ministry of Health, Nicosia, Cyprus

${ }^{\mathrm{n}}$ Larnaca General Hospital, Ministry of Health, Larnaca, Cyprus

${ }^{\circ}$ National Institute of Public Health (NIPH), Prague, Czech Republic and Charles University, Third Faculty of Medicine, Prague, Czech Republic

${ }^{\mathrm{p}}$ National Institute of Public Health (NIPH), Prague, Czech Republic

${ }^{\mathrm{q}}$ National Institute of Environmental Health (NIEH), Budapest, Hungary

${ }^{r}$ Centre de Recherche Public-Gabriel Lippmann (CRP-GL), Belvaux, Luxembourg

${ }^{s}$ Laboratoire National de Santé, Dudelange, Luxembourg

${ }^{\mathrm{t}}$ Nofer Institute of Occupational Medicine (NIOM), Lodz, Poland

u' Institute of Preventive Medicine, Lisbon Faculty of Medicine (IMP/FML), Lisbon, Portugal

${ }^{v}$ Environmental Health Centre (EHC), Cluj-Napoca, Romania

${ }^{\mathrm{w}}$ Public Health Authority of the Slovak Republic (UVZ SR), Bratislava, Slovakia

${ }^{\mathrm{x}}$ Institute of Environmental Medicine, Karolinska Institutet, Stockholm, Sweden

${ }^{y}$ Federal Office of Public Health (FOPH), Berne, Switzerland

${ }^{\mathrm{z}}$ Hainaut Vigilance Sanitaire (HVS) and Hygiene Publique in Hainaut (HPH), Mons, Belgium

aa National Environmental Health Office, Health Service Executive, Dublin, Ireland

${ }^{\mathrm{ab}}$ Health Service Executive, Environmental Health Department, Leitrim, Ireland

\footnotetext{
Abbreviations: ; BQ, Basic questionnaire; CAPI, Computer Assisted Personal Interview; COPHES, COnsortium to Perform Human biomonitoring on a European Scale; DEMOCOPHES, DEMOnstration of a study to COordinate and Perform Human biomonitoring on a European Scale; GerES, German Environmental Survey; HBM, Human

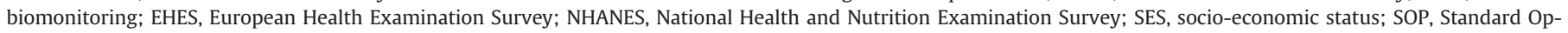
erating Procedure

* Correspondence to: Federal Environment Agency (UBA), Corrensplatz 1, D-14195 Berlin, Germany. Fax: +49 3089031830.

E-mail address: ulrike.fiddicke@uba.de (U. Fiddicke).
} 


\section{A R T I C L E I N F O}

\section{Article history:}

Received 29 May 2014

Received in revised form

12 August 2014

Accepted 15 August 2014

\section{Keywords:}

DEMO/COPHES

Lessons learned

Recruitment

Fieldwork

Human biomonitoring

\begin{abstract}
A B S T R A C T
Within the European Environment and Health Action Plan an initiative to establish a coherent human biomonitoring approach in Europe was started. The project COPHES (COnsortium to Perform Human biomonitoring on a European Scale ) developed recommendations for a harmonized conduct of a human biomonitoring (HBM) survey which came into action as the pilot study DEMOCOPHES (DEMOnstration of a study to COordinate and Perform Human biomonitoring on a European Scale). Seventeen European countries conducted a survey with harmonized instruments for, inter alia, recruitment, fieldwork and sampling, in autumn/winter 2011/2012. Based on the countries' experiences of conducting the pilot study, following lessons learnt were compiled: the harmonized fieldwork instruments (basic questionnaire, urine and hair sampling) turned out to be very valuable for future HBM surveys on the European scale. A school approach was favoured by most of the countries to recruit school-aged children according to the established guidelines and country specific experiences. To avoid a low participation rate, intensive communication with the involved institutions and possible participants proved to be necessary. The communication material should also include information on exclusion criteria and offered incentives. Telephone contact to the participants the day before fieldwork during the survey can prevent the forgetting of appointments and first morning urine samples. To achieve comparable results on the European scale, training of interviewers in all issues of recruitment, fieldwork and sampling through information material and training sessions is crucial. A survey involving many European countries needs time for preparation and conduct. Materials for quality control prepared for all steps of recruitment, fieldwork and sampling proved to be important to warrant reliable results.
\end{abstract}

(c) 2014 Elsevier Inc. All rights reserved.

\section{Introduction}

In the frame of the European Environment and Health Action Plan 2004-2010 (European Commission, 2004), the idea from the SCALE $^{1}$ initiative of 2003 to collect comparable European data on biomarkers of exposure of harmful chemicals through human biomonitoring was seized. As a result, harmonized guidelines were developed within the COPHES Project (COnsortium to Perform Human biomonitoring on a European Scale) (Joas et al., 2012). Shortly after, the pilot survey DEMOCOPHES (DEMOnstration of a study to COordinate and Perform Human biomonitoring on a European Scale) using these guidelines, was conducted in 17 European countries (Becker et al., 2014). The following countries participated in DEMOCOPHES: Belgium (BE), Switzerland $(\mathrm{CH})$, Cyprus (CY), Czech Republic (CZ), Germany (DE), Denmark (DK), Spain (ES), Hungary (HU), Ireland (IE), Luxemburg (LU), Poland (PL), Portugal (PT), Romania (RO), Sweden (SE), Slovenia (SI), Slovakia (SK), and United Kingdom (UK).

COPHES was constituted in December 2009 by 35 partners from academia, (governmental) agencies and stakeholders from 27 European countries that aggregated their experiences and expertize to develop a harmonized approach to conduct human biomonitoring on a European scale. It integrated specialists and experiences of the preceding project ESBIO (Expert team to Support BIOmonitoring in Europe) and the EU human biomonitoring Implementation Group ${ }^{2}$ which started harmonization of HBM on a European scale in 2004. Within ESBIO (funded under the $6^{\text {th }}$ framework program of the European Community) first general recommendations on study design, recruitment and field work for a HBM survey on the European scale had been developed. Within COPHES these harmonized procedures for human biomonitoring were further elaborated to make data from across Europe more comparable.

With the input of the 17 countries mentioned above, planning to conduct the pilot survey, a European consensus study protocol was developed (Casteleyn et al., this issue) and detailed Standard

\footnotetext{
${ }^{1}$ The EU Environment and Health Action Strategy SCALE (SCALE: Science, Children, Awareness, Legal instrument, Evaluation).

${ }^{2}$ ESBiO and Implementation Group: further information on: http://www.euhumanbiomonitoring.org/sub/esbio.htm
}

Operating Procedures (SOPs) were extracted to build the basis for the national DEMOCOPHES conduct. The 17 European countries started in autumn 2011 with the conduct of the harmonized HBM pilot survey. In this, 1844 children and their mothers participated. They filled in questionnaire data and provided first morning urine (for analyses of cadmium, phthalates and cotinine; Bisphenol A was additionally analysed by six countries) and scalp hair samples (mercury assessment) (Joas et al., 2012).

The aim of this article is to explain the main lessons learnt on transnational harmonization of recruitment and fieldwork during the conduct of DEMOCOPHES. Experiences and recommendations can serve as a model for further transnational cooperative HBM studies and thus facilitate production of comparable results and initiate burden sharing.

\section{Methods}

The way the study design, recruitment and fieldwork for the harmonized study protocol for COPHES and DEMOCOPHES was developed is already described by Becker et al. (2014). The main aspects of the whole harmonization process are described on the DEMO/COPHES webpages. ${ }^{3}$ In short, within COPHES harmonized protocols for i.a. selection of participants, recruitment, fieldwork and sample taking were developed and laid down as Standard Operating Procedures (SOP). The SOPs included all relevant information and recommendations for the conduct of a pilot HBMstudy on the European scale. Important tools developed were various questionnaires, e.g. the basic questionnaire (BQ), which covered inter alia the child's behavior and living conditions to elucidate the exposure pathways of the four substances in the focus of DEMOCOPHES (phthalates, mercury, cadmium and cotinine).

The COPHES SOPs and questionnaires served as the basis for the national SOPs and national questionnaires, which the countries participating in DEMOCOPHES had to transcribe by following the COPHES recommendations as closely as possible. All changes,

\footnotetext{
${ }^{3}$ DEMO/COPHES web-page pages: http://www.eu-hbm.info/cophes/pro ject-work-packages/wp2-sampling-recruitment-sample-collection and http:/ www.eu-hbm.info/democophes/objectives-and-project-tasks/task-2
} 
necessary due to country specific situations and preconditions, had to be announced to and accepted by the COPHES Central Management Unit.

To support the countries in developing their national SOPs, the COPHES scientists initialized a helpdesk enabling all countries to place their country specific questions. Additionally, a training session on fieldwork was organized in Berlin where representatives of the national studies were trained to train the respective fieldworkers (trainthe-trainer approach). During this training there was particular focus on providing study background, finalizing and training of the main instrument - the basic questionnaire. Hair sampling was also practiced. All training materials are available on the DEMO/COPHES web page. ${ }^{4}$

\subsection{Data sources}

During the study and after the fieldwork was finished, the countries had to report back on their conduct of DEMOCOPHES. The DEMOCOPHES coordinators sent questionnaires to the $\mathrm{Na}$ tional Management Units of each participating country designed to explain all aspects of study conduct. The first questionnaires covered the period from February 2011 till September 15th 2011 when most countries had not started the fieldwork but already received approval by their ethics committee. The second questionnaire-sequence covered July to October 2012, when the fieldwork and most of the data entry and some of the statistical evaluation were finished. The answers of the countries were laid down in so-called DEMOCOPHES Deliverables. ${ }^{5}$ The following lessons learnt are mainly based on the deliverables 'National Questionnaires' and 'National Report on sampling recruitment and sample collection'.

\section{Results}

\subsection{The recruitment process}

COPHES guidelines determined the study design, population groups of interest and the size of the study group(s) for DEMOCOPHES. A description of the decision processes within COPHES is described in detail by Becker et al. (2014). A cross-sectional survey was chosen as the most suitable study design. The vulnerable group of children, aged 6-11 years, and their mothers aged up to 45 years (in child-bearing age) were chosen as participants. In each participating country, 60 children and their mothers living in an urban area and 60 children and their mothers living in a rural area should participate, preferably covering all socio-economic status (SES)-groups. Smaller countries (CY, LU) required only half of the fixed number of participants. Based on these recommendations the recruitment process had to be planned in the 17 countries.

Prior to recruitment each country had to decide how to collect addresses of possible participants. Two options to get these addresses were accepted in the COPHES guidelines: retrieve addresses (1) from population registries or (2) via schools.

Within DEMOCOPHES just three countries chose the opportunity to obtain addresses of potential participants from official address registries and 14 countries chose the school approach. Different reasons led to the preference of the school approach, e.g. in some countries no public address registry was available or it was legally not allowed to ask for the addresses in such a registry.

\footnotetext{
${ }^{4}$ http://www.eu-hbm.info/cophes/project-work-packages/ trainings-agendas-and-presentations

5 See for more information the DEMOCOPHES Technical report on http://www. eu-hbm.info/democophes
}

Some countries started with a registry approach but - due to an extremely low participation rate - switched to the school approach.

1. Lesson learnt: 14 of 17 countries chose the school approach to recruit the children so that the school approach should be favoured for European surveys with children of primary school age.

In the course of COPHES the SOP "Selection of Participants" was developed. It explained all necessary steps for the school and the registry approach in detail. Due to the experiences during the selection process, the following text focuses on the school approach.

The 14 countries using the school approach had different degrees of experience and different organizational requirements; therefore they chose diverse ways for the single phases of the participant recruitment process. An overview is provided in Table 1.

Table 1

Alternative strategies of the DEMOCOPHES countries for single actions during the recruitment process within the school approach.

Alternative strategies of the different phases of the school approach

Involvement of superior school authorities

- Superior school authority contacted by the field staff.

- School principal contacted superior authority and asked for permission.

- No superior school authority involved.

Selection of the school

- The only one school in that area was chosen.

- The school was randomly selected out of all public schools listed in the selected area.

- Schools that wished to participate were taken.

- Schools with established contacts to the scientists were chosen.

Information of the teachers

- School principal informed first, main information by survey staff.

Initial contact to possible participants

- Parent's evening with or without teacher especially for this issue or regular parent's meetings.

- Survey staff informed the pupils in the class.

- Teacher informed the pupils in the class.

- Personal contact at school entrance.

- Article in local newsletters.

Distribution of the Invitation material

- No material provided-information at parents evening followed by direct decision about participation.

- Invitation and information material was given to parents at parents evening.

- Invitation and information material was distributed by the teachers to the pupils in the class.

- Invitation and information material was spread via school intranet and school newsletter.

Way of maintaining contact to the pupils and their parents

- Via letters: second invitation letter; appointment letter.

- Via phone: phone contact (phone number via school secretariat or from returned reply card).

- Via email/internet: personal email or information on school web-site.

- Via teacher: teacher reminded on returning reply card.

Distribution of material needed for sampling (urine vessels)

- Mailed via individual post.

- Mailed to a central address (town hall/school), participants picked it up there.

- Personally delivered and collected. 


\subsubsection{Contacting schools and children}

In all but three countries, contacting children via schools demanded the involvement of superior school authorities who were partly contacted by the field staff directly and partly by the school principals (see Table 1). The way schools were selected and the way school principals and teachers were asked to participate also differed. In many procedures (e.g. providing initial study information to the pupils and/or parents, distribution and collection of the invitation and other written material) teachers had to be involved and the success of the recruitment process depended largely on the teachers commitment and support. Additionally, children who wanted to take part encouraged others to participate. One common experience the countries reported was the importance of the interest of the superior school authority or school principal: if they were interested the conduct of DEMOCOPHES was mostly a success. Teachers had a similar influence: more parents responded if the teachers repeatedly reminded the children to return the reply card, a kind of post card handed out to the pupils for their parents to give them the possibility to express their interest in taking part or not.

\subsubsection{Flexible recruitment recommendations}

As already noted, Table 1 describes the different methods used by the participating countries to contact and recruit the children. Different strategies were necessary to reach the aim of recruiting 60 children of 6-11 years in each of the two sampling locations. Sometimes the teachers or school principals advised on the best ways how to contact the pupils, which indicates the necessity of some flexibility in recruitment recommendations.

The COPHES recommendations included recruiting equal numbers of children in each of the 6 age groups, equal proportions of boys and girls and if possible covering different SES-groups. This resulted in extra effort for the field staff since oversampling could occur for some subgroups. Some countries included those surplus volunteers in their study - in one country the ethical committee demanded to offer analyses also to the siblings - but did not report their results to DEMOCOPHES. Preferably state-funded schools were selected, to fulfill the recommendation to cover several SES groups.

DEMOCOPHES did not aim to recruit a representative population sample of the country but some aspects of representativeness regarding the selection of the schools and the pupils should be regarded if possible. The countries worked hard to achieve an as near as possible representative sample of the pupils of that region, but sometimes rural areas for participant recruitment had to be enlarged to get enough children or, in two countries, fieldworkers directly approached mothers at the school gate with children in the required age groups to fill up the missing participant groups. Finally, two countries did not reach the desired participant numbers.

2. Lesson learnt: If number, age and gender of the target population sample are fixed, recommendations for the recruitment process should allow flexibility in a given frame to enable the participating countries to reach the fixed numbers.

\subsubsection{Exclusion criteria/communication}

After the parents had agreed to participate, a recruitment interview was conducted via phone with the aim to select eligible participants according to defined inclusion and exclusion criteria, respectively. Exclusion criteria were:

- Mothers born before 1966 (i.e. age of 46 years or higher); children born before 2000 and after 2005 (i.e. younger than 6 or older than 12 years).
- Living for less than 5 years in the sampling location.

- Being homeless or living in children's or nursing homes;

- Mother and child living together less than 16 days per month.

- Insufficient ability of the mother to communicate in the national language.

- Disease of inner organs (kidney, liver).

- Being a sibling of a selected child (to avoid that information from one household (e.g. concerning the heating system) weighs multiple in the analysis).

In some countries it was difficult to meet the inclusion criterion with respect to the age of the mother, since many mothers of primary school children were older than 45 . An extension of this age limit may be advisable in next studies. Some of the interested participants were not aware of all the exclusion criteria and therefore were disappointed or really upset when confronted with being excluded e.g. because the mother did not meet the age criteria. In one country men were disappointed not to be able to provide samples, too. This revealed that clear communication of exclusion criteria in the very first documents and contact is crucial to inform the participants completely and be clear about the criteria. Furthermore, communication via different media and at different occasions is necessary to increase the participation rate which was rather low and varied between $4.8 \%$ and $66.7 \%$ among the countries.

3. Lesson learnt: Clear communication of exclusion criteria in the first documents and contacts is crucial so as not to upset volunteers. Furthermore, a widespread communication campaign supports reaching an acceptable participation rate.

\subsection{Fieldwork}

\subsubsection{Informed consent}

To obtain knowledge about exposure pathways for the selected biomarkers, the interviews and the collection of first morning urine and scalp hair samples of the participants were the main instruments of fieldwork. Ethical rules required that participants (parent of the child) signed the informed consent prior to the start of the fieldwork. This was accomplished by all countries. The timing of signing the consent form varied in the countries: two countries had the signed consent form returned by the participants by mail prior to the day of the interview, the others had the participants sign the consent form right at the beginning of the visit for the interview. In one country most forms were signed in advance but the ethics committee required the informed consent form to be signed again at the beginning of the visit.

4. Lesson learnt: For practical reasons it is most suitable for participants and interviewers if the signed informed consent form is collected directly at the beginning of the visit for the interview.

\subsubsection{Site of the interview - at participant home or at an ex- amination center}

The COPHES recommendations included a face-to-face interview with the mothers to get information about exposure pathways and the socio-economic situation of the family. All countries except two offered two options for the interview conduct: conduct of the interview at the family home or at an examination center. The home visit was recommended as the preferred option because it was considered useful to test the feasibility of a home visit for future surveys, which may wish to include monitoring of the participant's living environment (like tap water or air sampling) in 
the home. The final choice of the interview site was left to the mothers depending on their preferences. This preference varied from country to country. Some mothers preferred to be visited at home, others preferred to visit an examination center (e.g. a room in the school); sometimes the preferred choice varied between the urban and the rural area. In four countries all mothers wanted to be visited at home. No clear recommendations for the preferred interview site can be given.

5. Lesson learnt: A survey should preferably offer at least two options for the conduct of a face-to-face interview for the convenience of the participants. If monitoring of the participant's living environment is included in the survey, a visit at the homes will be obligatory.

\subsubsection{Flexibility of appointments/sampling}

One experience the DEMOCOPHES countries had, was that the fieldwork staff had to provide interview hours all over the day, throughout the week (except Sunday) and be flexible with sudden unintended changes or drop outs of appointments. Appointments for interviews should always be fixed in accordance with the needs of the participants; especially working mothers who have tight personal schedules.

Matrices for the biomarker analyses were first morning urine and scalp hair. Participants were provided with sampling vessels and instructions on how to sample first morning urine on the day of the interview. In some countries a lot of participants forgot to collect the urine sample which is why another appointment to fetch the urine sample was necessary (extra work for the fieldworkers). Calling the participants the day before the interview to remind them on the appointment and on the urine sampling helped to reduce the numbers of forgotten samplings and appointments.

The hair sampling was done by the interviewers directly prior to the basic interview. The countries only reported some small problems with sampling, particularly with very short hair of some boys. All interviewers had undergone training on hair sampling which had prepared them very well for such difficult circumstances.

\section{Lesson learnt:}

(1) Flexibility in arranging appointments and in reacting to sudden schedule changes is necessary to keep the participants in the survey.

(2) Calling the participants the day before the interview reduces the workload resulting from forgotten appointments or forgotten urine sampling.

(3) Intensive training of the interviewers is especially necessary for complicated procedures such as taking hair samples.

\subsubsection{Face-to-face interview with the basic questionnaire}

The main instrument of fieldwork was the basic questionnaire (BQ). It was developed especially for the demands of DEMOCOPHES, i.e. covering the exposure pathways for the four biomarkers of interest (cadmium, cotinine and metabolites of 5 phthalates in urine and mercury in hair). The BQ consisted of 6 sections, addressed to the mother but also including questions for the child (Table 2).

The BQ was designed as a face-to-face interview with the mother. To enable all involved interviewers to understand the importance and underlying meaning of the questions, the basic questionnaire was accompanied by a background paper. This background paper explained each question, gave additional information for the interviewer and listed the reference questionnaires. Besides this written information a two-day training session was organized. Each country had sent at least one member of the national field staff to the training session to be able to train additional national interviewers on the questionnaire. This training was also used for a last fine-tuning of the wording of the questions.

Like other documents produced within COPHES, the participating countries had to adapt and translate the BQ to each country's individual needs. This procedure consisted of two steps: (1) the BQ had to be adapted to special country needs (all in all 8 smaller changes spread over 6 countries e.g. concerning the heating system or the income categories used) and (2) the BQ had to be translated into the national language(s). For this, it was recommended that translation professionals should be hired and afterwards the translation should be controlled by the survey scientists. It was recommended that each country trained their interviewers on the basic questionnaire and performed some test interviews with the translated questionnaire. All countries reported back about their experiences and confirmed the importance of these trainings.

During the face-to-face interview with the mother, the trained interviewers were obliged to read the questions verbatim in a predefined order. Except two countries, all countries performed the $\mathrm{BQ}$ as the recommended face-to-face interview. Thanks to the involvement of all countries in the questionnaire development, the interviewers experienced that the basic questionnaire was a well elaborated instrument. Just single questions, especially those based on EUROSTAT classifications (occupation and socio-demography, respectively), were difficult to answer for mothers in nearly all countries. These classifications should have been better transformed to the specific situation in the countries and be translated into layman's terms.

The recommendation that some questions are obligatory (e.g. smoking habits) and that at least $80 \%$ of the questions must be answered by a family to count as a case was retracted in the course of the fieldwork because it showed to be impracticable to insist on answering obligatory questions. Furthermore, interviewers

Table 2

Sections of the basic questionnaire.

\begin{tabular}{|c|c|}
\hline Section & Content \\
\hline A: Residential environment and residence & $\begin{array}{l}\text { Construction year, square meters of living space, description of living area, vicinity to incineration or other industry, } \\
\text { heating system, energy source, renovation or redecoration of the home, flooring and wall paper material. }\end{array}$ \\
\hline B: Nutrition & Main source of water supply, alcohol consumption, average frequency of selected food items in the last four weeks. \\
\hline C: Smoking behavior & Active, passive and former smoking. \\
\hline D: Exposure relevant behavior & $\begin{array}{l}\text { Use of cosmetics, contact to hazardous material during free time, breaking of mercury thermometer or energy saving } \\
\text { lamp, amalgam fillings, time spent in a car, age of car, time spent outside, contact to rubber like plastic via gloves or toys. }\end{array}$ \\
\hline E: Occupation (of the mother) & Kind of job, work environment. \\
\hline F: Socio-demography & $\begin{array}{l}\text { Single mother, immigrant, language spoken at home, education by ISCED-code, professional status, position presently } \\
\text { hold, income category. }\end{array}$ \\
\hline
\end{tabular}


reported that it was impossible to estimate how many questions a family had already answered during the course of the interview if some questions were skipped. For future surveys some countries demanded online questionnaires (two countries already applied them), to save some time or to enable the participants to check for difficult answers in advance (e.g. questions the mothers lack the information, like the age of the building). Online questionnaires or self-administered questionnaires will require different elaborations and explanations which have to be accounted for already during the development.

7. Lesson learnt: The experience illustrated that the provided basic questionnaire was a well elaborated instrument and applicable for the purpose of the study. It also revealed that it is worthwhile to involve all participating countries in the finalization of the questionnaire to receive a well-adapted questionnaire. To offer not only written training materials but also a training workshop especially for the survey specific questionnaire (BQ) turned out to be important for a good performance of the face-to-face interview. Future surveys should consider the possibility to use online (web based) self-administered questionnaires.

\subsubsection{Computer assisted personal interview (CAPI)}

The use of a CAPI with constant internet access instead of paperand-pencil for the face-to-face interview was introduced in the COPHES recommendations. The CAPI should only be used by the interviewers, to read the questions and to record the answers. This recommendation was set but not until shortly before the beginning of the fieldwork period, and a specific CAPI-system was provided to be used by all countries willing to use a CAPI to assist the interviewers. Due to this late introduction of the system and technical prerequisites (constant internet access) the chosen system could not be used in all involved regions. Additionally the system broke down if several countries were using it simultaneously. Some countries could not use this system because the national data protection requirements hindered the use of this online system which stored the data on an American server. Some countries used the system only for data entry after having performed the interview with pencil and paper and were very satisfied with it, though this resulted in considerable extra working hours, because it was of help in checking the quality of the data. One country applied an off-line CAPI system with specially designed software (Ligocka et al., this issue).

8. Lesson learnt: If a computer assisted personal interview (CAPI) is to be used for the face-to-face interview, the selection of the system has to be in an early stage of the process and has to consider the different requirements of the participating countries, e.g. data protection requirements and internet accessibility. A constant accessibility and stability of the systems' server is required, if all members shall be online simultaneously.

\subsubsection{Schedule of the visit/duration of the visit}

COPHES guidelines recommended that the procedure of fieldwork should follow a relatively strict schedule: after collecting the signed informed consent and addressing any last questions about the survey, the urine samples of mother and child should be received and a short questionnaire related to the urine sampling answered. After this, hair samples of mother and child should be taken and a short inquiry related to hair sampling should be started. Only after these procedures should the interview with the basic questionnaire be performed. This schedule was recommended because it was expected that participants would more likely withdraw from giving these samples than from being interviewed. It would be a waste of time if the participant had
Table 3

Minimum, maximum and median duration of the basic questionnaire interview, the whole home visit and the whole visit at the examination center, respectively, in DEMOCOPHES

\begin{tabular}{lcrl}
\hline & Min & Max & Median \\
\hline Duration of basic questionnaire conduct (min) & 15 & 90 & 40 \\
Duration of the whole home visit & 45 & 135 & 60 \\
Duration of whole visit at examination center & 45 & 90 & 60 \\
\hline
\end{tabular}

refused to give a hair sample after the long interview had been performed. In those countries that provided the online version of the basic questionnaire this schedule was not followed, the other countries did not report deviations. Some countries wanted to ask additional questions (e.g. about Bisphenol A exposure pathways) and two countries wanted to take blood samples. Those additional procedures were scheduled after all other procedures so that e.g. the additional blood sampling did not interfere with the basic DEMOCOPHES procedure. The whole procedure should be finished by handing over the gifts of appreciation (incentives), if licit, and a grateful good bye. DEMOCOPHES demonstrated that this schedule was suitable and the whole process feasible, only one country reported changes on the schedule. The two countries that used an online version of the BQ went through the provided answers in the scheduled interview time.

During the preparation of the basic questionnaire, doubts concerning its length arose. Some countries were concerned that participants would not accept the anticipated duration of 60 minutes (additional time would be necessary for the hair sampling etc.). In the evaluation 12 countries reported that few contacted mothers did not want to spend their time for the program and refused participation. On the other hand the time needed for answering the questionnaire revealed to be shorter (median of 40 minutes) than in the test phase (60 min) (Table 3). Generally, a compromise has to be found between the scientific need for detailed questions and the burden for the participants. Some DEMOCOPHES countries found that the time needed was reduced once the interviewers become more experienced in the process.

9. Lesson learnt: The COPHES SOP for fieldwork was a well suited instrument for the collection of the data needed for this pilot European human biomonitoring survey and might be used as a blueprint for future surveys. The duration of the visit should be estimated soundly so that possible participants can reliably judge the burden of participation.

\subsubsection{Incentives or gifts of appreciation}

COPHES guidelines recommended giving an incentive or gift of appreciation at the end of the visit additionally to providing the results of the urine and hair analyses. However, at the beginning of DEMOCOPHES uncertainty existed as to whether the ethical committees of all countries would permit providing these token of thanks for the participants. During DEMOCOPHES this question was answered: all ethical committees involved allowed incentives or token of thanks to be provided, at least non-monetary. In fact one ethical committee recommended handing over monetary incentives. Two countries did not offer incentives because their budget did not allow it. All others had small objects (pencils, erasers, umbrellas etc.) or monetary gifts (shopping vouchers (from $6 €$ to $50 €$ ), cinema tickets) to thank the participants. Two countries additionally provided gifts to all pupils who returned the reply card to the teacher (no matter if they agreed to participate or not) and those countries reported a positive influence of incentives on answering. Only two countries reported the necessity of reimbursement of travel expenses to the examination centers. 
10. Lesson learnt: If legally (ethically) allowed incentives should be offered and should be announced in the invitation letter (to have a positive effect on the participation rate). The costs for incentives should be foreseen in the study budget.

\subsubsection{Duration of the whole DEMOCOPHES fieldwork process}

To avoid seasonal bias the COPHES recommendation was that the survey should be conducted in all 17 countries within a given time frame of three months in autumn/winter 2011/2012. Ethical approvals and data protection issues caused a delay at the beginning and the recruitment process needed longer than expected. Four countries finished the fieldwork within the given time frame, 8 countries exceeded it roughly for one month, three countries had a delay of two months and one country a delay of 4 months.

11. Lesson learnt: Enough time for recruitment and conducting the fieldwork has to be considered if a study shall be conducted in several countries in parallel.

\subsubsection{Quality assurance methods}

Detailed descriptions of important steps of recruitment, fieldwork and sampling were laid down in COPHES SOPs designed as masters for the country specific SOPs. SOPs could be used on the one hand for the preparation of the fieldwork in each country and on the other hand as training material for the interviewers. SOPs provided information on procedures and on material necessary for the survey conduct, which had to be produced or purchased (written material, material for sampling, etc.). As recommended by the German Society for Epidemiology (2011), COPHES suggested to compile a folder (Fieldwork Manual=operation manual) containing all the produced material (e.g. invitation letter, description on urine sampling, etc.) and the description of the purchased material (e.g. gloves and scissors) as well as all SOPs.

National Fieldwork Manuals as an important quality control measure were implemented in nearly all countries to support the quality control and training. Further quality control methods included check lists for the procedure of the visits at the homes and the examination centers, which were also provided by COPHES and in the original or an adapted version were widely used in the countries. Internal field visits were recommended and check lists for these visits provided. In larger surveys external field visits are also part of the quality assurance system but it was decided to waive the external field visits because of the pilot character of DEMOCOPHES.

The main quality assurance measure was the training of the interviewers. This training was crucial for the success of the survey as it included special training units on all issues of recruitment and fieldwork, including hair sampling. The training allowed highlighting the critical points and harmonizing the sampling procedure. It is with thanks to the DEMOCOPHES countries, using nearly all information, applying diverse robust quality assurance measures and following the recommendations whenever possible, that a high quality standard of the DEMOCOPHES results can be assured.

12. Lesson learnt: Diverse quality assurance measures are crucial for creating reliable results and therefore support for quality control of recruitment and fieldwork should be offered.

\section{Discussion}

Seventeen European countries demonstrated the feasibility of conducting a European environmental human biomonitoring (HBM) survey according to harmonized guidelines developed within the DEMO/COPHES projects. This was the first time, comparable HBM data per se and in combination with information on exposure pathways and the participant's socio-economic status could be collected in Europe. The preparation of the harmonized guidelines already started in 2004 with the establishment of the first working groups on HBM (Implementation Group and ESBiO) in the frame of the European Environment and Health Action Plan. It took until December 2009 till the Consortium to Perform Human Biomonitoring on a European Scale (COPHES) began to elaborate in detail the recommendations based on which the planning of the pilot study DEMOCOPHES started in September 2010. Preparing the common study protocol, the tailored questionnaires, the analysing laboratories and all the written materials took until August 2011. Recruitment of DEMOCOPHES participants and fieldwork started in September 2011 and it lasted until April 2012 till all countries completed the fieldwork.

The frameworks for the harmonized recruitment and fieldwork procedures were established within COPHES, elaborated mainly under the lead of the German Federal Environment Agency (UBA). UBA as well as other COPHES members could contribute not only because of already being members of the Implementation Group and ESBiO but also because of their considerable experience gained in HBM at regional or national level. UBA e.g. gained experience in the German environmental surveys (GerES) (Schulz et al., 2007) and especially in the last survey, GerES IV, a survey on Children (Becker et al., 2007; Kolossa-Gehring et al., 2007). Experiences of other COPHES members come e.g. from the Flemish human biomonitoring program in Flanders (Schoeters et al., 2012) or from a pilot human biomonitoring study in Spain (Castaño et al., 2012).

DEMOCOPHES was a pilot study aiming to test the feasibility of the harmonized approach. For the conduct of this pilot study the 17 participating countries chose different options possible within the frame of the given recommendations including modifications according to the national needs. All modifications of the harmonized EU study protocol and elaborated SOPs, partly necessary to enable the countries participation, had to be assigned to and accepted by COPHES. All changes the countries announced were accepted by COPHES as the changes were not expected to interfere substantially with a harmonized approach. Examples for such changes are use of differing sampling vessels, invitations and recruitment via internet, to forego the offer of home visits because, e.g. an 'Environment and Health' day was celebrated at the selected school.

The conduct of DEMOCOPHES provided several lessons learnt, starting with the recruitment process: Organizing a European survey on children revealed to be easier if children were contacted via schools because access to officially collected address data (inhabitant or population registers) is only possible for a very limited number of European countries. However, involving schools proved to be sometimes a challenge because in addition to encouraging children and parents to participate, the teachers, school principals and sometimes superior school authorities had to give their permission. This experience is supported by literature. Geller et al. (2007) described very well the complexity of the school approach in the United States. Their lesson learnt is that planning and implementation of school studies must include all levels of administration and a grassroots approach. Post et al. (2003) mentioned that the school approach is considered as highly efficient in recruiting children but non-participation of entire units (e.g. whole schools or classes) is common. Phipatanakul et al. (2011) reported in their lessons learnt from the School Inner-City Asthma Study that convincing the schools was a hard job and had to be repeated every time new schools were included in the study. Therefore they concluded that efforts to engage the school staff in support of the survey have to be increased. DEMOCOPHES countries made good 
experiences with involving local authorities in rural areas because this raised the confidence in the survey. Different approaches to recruit (representative) population samples are e.g. used in NHANES (CDC, 2013). There, children are contacted together with their parents using a map-frame to select the households for participation. Another representative approach is used in the pilot European Health Examination Survey (EHES) (Heldal and Jentoft, 2013). In a two-stage sampling design the sample of individuals to be invited is obtained: firstly the area is selected and secondly people, addresses, households or dwellings are selected; but EHES only covers adults.

Clear communication of the exclusion criteria right at the beginning of the recruitment process appeared to be important because some selected families turned away disappointed when they finally realized that they did not meet the inclusion criteria - this could also upset volunteers in future surveys. Some countries accepted all volunteers but only reported the results for the originally selected ones back to DEMOCOPHES to avoid complications. It can be summarized that for a European harmonized recruitment process tight restrictions are not necessary if target groups and sample size are defined. A degree of flexibility that does not compromise the results comparability can yield in an improvement of the recruitment process results.

DEMOCOPHES also contributed lessons learnt to the fieldwork procedure, e.g. concerning the structure and schedule of the home visit: The procedure of the home visit (or visit of the examination center) was structured in the parts (1) sampling (respective collecting sample vessels) and (2) interview, with clear recommendations on how to perform the questionnaires (read questions verbatim in the predefined order). These exact recommendations were very useful for a timesaving procedure and were followed by nearly all countries. The basic questionnaire developed with the support of the participating countries proved to be a suitable instrument. Within the preparation phase of the questionnaire some countries discussed whether the questionnaire was too long - from a scientific view others wanted to add some questions. Experience in DEMOCOPHES showed, that the duration was on average 40 minutes and decreased with the experience the interviewers gained. The whole visit took $60 \mathrm{~min}$. Adgate et al. (2000), of the cross-sectional Minnesota Children's Pesticide Exposure Study which dealt with multi-pathway and multi-pesticide exposures, experienced that a duration of a visit of less than $1 \mathrm{~h}$ is important for the compliance of the participants.

Some minor lessons learnt to keep in mind are (a) to sign the informed consent only at the beginning of the participant visit (no returning via mail in advance); (b) to offer both home visits and visits in examination centers for the convenience of the participants and (c) to call the participants the day before the visit to remind them of the appointment and the urine sampling. Being flexible in fixing appointments with the participants and changing them if necessary at short notice, is also important to achieve a high participation rate. This is supported by experiences from Austria and the United States. An Austrian survey (Hohenblum et al., 2012) suffered from a low participation rate of $4 \%$, mainly due to a fixed fieldwork week without possibility to change to another week. Morris et al. (2012) described their experiences of being an interviewer in the United States, clearly showing the necessity to react flexibly. The interview can be performed with pencil and paper or with assistance of a laptop. If a CAPI system is used it should be a flexible system not based on the internet and cover all requirements of the participating countries. It can be summarized that for a European harmonized fieldwork procedure the procedure developed within the DEMO/COPHES projects can be used as a prototype.

Another procedure belonging to fieldwork and with influence on the participation rate is the handing over of incentives or gifts of appreciation. Prior to the ethical approval it was unknown if each country was allowed to offer incentives in gratitude for participation. Needham and Sexton (2000) reported in an overview of selected United States research challenges for assessing children's exposure to hazardous environmental chemicals that depending on the involved ethical committee incentives may be provided or not. Incentives are mostly allowed to reimburse participants for expenses and burdens, they are often necessary to encourage participants to volunteer, so they should be provided if possible (Needham and Sexton, 2000; Geller et al., 2007). Incentives should be mentioned in the very first information leaflets, in order to attract participants and raise the participation rate which was rather low in DEMOCOPHES where incentives were handed out at the end of the interviews and were not announced in the invitation letters. Jacob and Jacob (2012) showed that even school principals could be easily convinced to participate in a survey if monetary incentives (US \$10) were provided. Phipatanakul et al. (2011) described the value of additional incentives on participation rate of school children. DEMOCOPHES unveiled that in all participating countries the ethics committees allowed to provide incentives as reward for the inconveniences the participants incurred - at least non-monetary incentives. But it is necessary to follow the principle of voluntary participation which requires that people are not coerced into participating in research (Sepai et al., 2008). In two countries the information on the analytical results that all participants received served as the only incentive. But as Eggleston et al. (2005) reported, this is not negative: Sometimes information provided to the participants attracted them most to the study, more than other offered incentives. Theses authors also described that reimbursements for electricity costs during the survey (up to US \$200) or reimbursements for travel expenses are common.

Communication activities are an important measure to improve the participation rate. Phipatanakul et al. (2011) and Kimmel et al. (2005) emphasized the necessity of improved communication but Adgate et al. (2000) were confronted with a lack of interest of the local media in press-releases about a planned survey because the media was only interested in results. Instead, Adgate et al. (2000) were more successful in recruiting families by direct contact of potential participants. One participating DEMOCOPHES country demonstrated the importance of active communication and interest raising on participation rate: in Poland the survey team organized a special school event day where they presented information and actions on environment and health and invited the pupils and their parents in the selected age groups - this resulted in a four-fold higher response rate compared to other countries. In Luxembourg the Minister of Health invited the press into his office for a press conference during the kick-off period that resulted in national press and media coverage and potentially raised awareness in the population (Katsonouri et al., this issue).

The most important lesson learnt from DEMOCOPHES is the importance of the interviewers and their training. They are the key to reliable results (Morris et al., 2012). Furthermore, interviewers and their attitude towards respondents also influence the response rate and survey results (Davis et al., 2010; Blom et al., 2011). These influences are different in different countries (Blom et al., 2011). Also experienced interviewers have to be trained on each survey instrument - the questionnaire and the sample taking. Davis et al. (2010) query what is defined as "experienced". Different definitions of 'high' or 'low' experienced interviewers exist and it has to be defined which kind of experience is considered. Thus, training is important, even more if a "building capacity" objective has to be considered. Training has to include practical training on the instruments and should be accompanied by test-interviews to practice the whole procedure. The training workshop for DEMOCOPHES implementing countries was a valuable instrument for process harmonization.

The interviewer training was the main quality assurance measure during fieldwork. It increased the likelihood that all involved interviewers worked the same way, which for fieldwork is 
as important as the quality assurance measures for chemical analysis (such as round-robin tests or external and internal quality comparisons, Schindler et al., 2014). Besides training, further methods of quality control (e.g. internal and external field visits) should also be offered.

Finally, DEMOCOPHES showed that recruitment and field work needed time - more time than expected.

\section{Conclusions}

The pilot study DEMOCOPHES revealed that with the help of the instruments and recommendations for recruitment, fieldwork and sampling developed within COPHES, 17 European countries succeeded in the harmonized conduct of an environmental HBMsurvey. Not tight restrictions but recommendations that allow country specific adaptations are the key to harmonization.

The above mentioned lessons learnt will help to further progress the future of European HBM-surveys that involve children, potentially leading to a European HBM-Monitoring. Great importance should be attached to soundly elaborated survey instruments and materials and - if face-to-face interviews are to be used - to interviewers who are well trained, especially in all aspects of the survey and the survey instruments. Future HBM-programmes will help to improve the environmental health of people living in Europe by identifying critical exposure to chemicals and their sources as well as by deriving risk reduction measures.

\section{Acknowledgments}

We wish to thank the European Commission, DG for Research and Innovation (RTD) who funded COPHES in the 7th Framework programme (No. 244237) and DG Environment, who co-funded DEMOCOPHES under the LIFE + Programme (50\% - LIFE09 ENV/BE/000410) and partners from 21 countries. Information on the national cofunding institutions is accessible via the 'Partners' page of the DEMOCOPHES website: http://www.eu-hbm.info/DEMOCOPHES/pro ject-partners. We would also like to thank all project partners and all ministries and institutions, and other research groups in the European Member States, other European countries and countries worldwide that supported the project with information and experience. Last but not least we are grateful to the families for participating in the DEMOCOPHES study. Updated information on the projects can be derived from the project website http://www.eu-hbm.info/.

\section{References}

Adgate, J.L., Clayton, C.A., Quackenboss, J.J., Thomas, K.W., Whitmore, R.W., Pellizzari, E.D., Lioy, P.J., Shubat, P., Stroebel, C., Freeman, N.C., Sexton, K., 2000. Measurement of multi-pollutant and multi-pathway exposures in a probabilitybased sample of children: practical strategies for effective field studies. J. Expos. Anal. Environ. Epidemiol. 10, 650-661.

Becker, K., Seiwert, M., Casteleyn, L., Joas, R., Joas, A., Biot, P., Aerts, D., Castano, A Esteban, M., Angerer, J., Koch, H.M., Schoeters, G., Den Hond, E., Sepai, O., Exley, K., Knudsen, L.E., Horvat, M., Bloemen, L., Kolossa-Gehring, M., 2014. DEMOCOPHES consortium. A systematic approach for designing a HBM pilot study for Europe. Int. J. Hyg. Environ. Health 217, 312-322.

Becker, K., Schulz, C., Basisch, W., Dürkop, J., Rosskamp, E., Seiwert, M., Szewzyk, R. Ullrich, D., Seifert, B., 2007. German environmental survey for children (GerES IV) 2003-2006. Pollut. Atmos. 94, 475-479.

Blom, A.G., de Leeuw, E.D., Hox, J.J., 2011. Interviewer effects on nonresponse in the European Social Survey. J. Off. Stat. 27, 359-377.

Castaño, A., Sanchez-Rodriguez, J.E., Canas, A., Esteban, M., Navarro, C., RodriguezGarcia, A.C., Arribas, M., Diaz, G., Jimenez-Guerrero, J.A., 2012. Mercury, lead and cadmium levels in the urine of 170 Spanish adults: a pilot human biomonitoring study. Int. J. Hyg. Environ. Health 215, 191-195.

Casteleyn, L. et al., 2014. A pilot study on the feasibility of the European human biomonitoring framework and programme: challenges and opportunities, this issue.
Centers for Disease Control and Prevention (CDC), 2013. Key Concepts About NHANES I Sample Design. 〈http://www.cdc.gov/nchs/tutorials/NHANES/Survey Design/SampleDesign/intro_i.htm $\rangle$ (accessed 23.04.14.).

Davis, R.E., Couper, M.P., Janz, N.K., Caldwell, C.H., Resnicow, K., 2010. Interviewer effects in public health surveys. Health Educ. Res. 25, 14-26.

Eggleston, P.A., Diette, G., Lipsett, M., Lewis, T., Tager, I., McConnell, R., Chrischilles, E., Lanphear, B., Miller, R., Krishnan, J., 2005. Lessons learnt for the study of childhood asthma from the Centres for Children's Environmental Health and Disease Prevention Research. Environ. Health Perspect. 113, 1430-1436.

European Commission: Environment and Health Action Plan, 2004-2010. 〈http:// ec.europa.eu/health/healthy_environments/policy/health_environment/action plan_en.htm $>$ (accessed 23.04.14.)

Geller, A.C., Oliveria, S.A., Bishop, M., Buckminster, M., Brooks, K.R., Halpern, A.C., 2007. Study of health outcomes in school children: key challenges and lessons learnt from the Framingham Schools' natural history of nevi study. J. Sch. Health 77, 312-318.

German Society for Epidemiology (DGEpi), 2011. Guidelines and Recommendations to Assure Good Epidemiologic Practice (GEP). 〈http://dgepi.de/berichte-und-pu blikationen/leitlinien-und-empfehlungen.html (accessed on 23.04.14.).

Heldal, J., Jentoft, S., 2013. Target population and sample size. In: Tolonen, H. (Ed.), EHES Manual, Part A. Planning and Preparation of the Survey. 〈http://www. julkari.fi/bitstream/handle/10024/104393/URN_ISBN_978-952-245-842-1.pdf? sequence $=1\rangle$ or $\langle$ http://www.ehes.info/manuals/EHES_manual/EHES_manual. htm〉 (accessed on 23.04.14.).

Hohenblum, P., Steinbichl, P., Raffesberg, W., Weiss, S., Moche, W., Vallant, B., Scharf, S., Haluza, D., Moshammer, H., Kundi, M., Piegler, B., Wallner, P., Hutter, H.P., 2012. Pollution gets personal! A first population-based human biomonitoring study in Austria. Int. J. Hyg. Environ. Health 215 (2), 176-179.

Jacob, R.T., Jacob, B., 2012. Prenotification, incentives, and survey modality. An experimental test of methods to increase survey response rates of school principals. J. Res. Educ. Eff. 5, 401-418.

Joas, R., Casteleyn, L., Biot, P., Kolossa-Gehring, M., Castano, A., Angerer, J., Schoeters, G., Sepai, O., Knudsen, L.E., Joas, A., Horvat, M., Bloemen, L., 2012. Harmonised human biomonitoring in Europe: activities towards an EU HBM framework. Int. J. Hyg. Environ. Health 215, 172-175.

Katsonouri, A. et al., 2014. Applying human biomonitoring in small populations: a roadmap based on the European human biomonitoring pilot study experience, this issue.

Kimmel, C.A., Collman, G.W., Fields, N., Eskenazi, B., 2005. Lessons learnt for the National Children's Study from the National Institute of Environmental Health Sciences/U.S. Environmental Protection Agency Centers for Children's Environmental Health and Disease Prevention Research. Environ. Health Perspect. $113,1414-1418$.

Kolossa-Gehring, M., Becker, K., Conrad, A., Lüdecke, A., Riedel, S., Seiwert, M., Schulz, C., Szewzyk, R., 2007. German Environmental Survey for Children (GerES IV)-first results. Int. J. Hyg. Environ. Health 210, 535-540.

Ligocka, D. et al., 2014. Assessment of environmental exposure to cadmium and the contribution of twin projects DEMOCOPHES and COPHES in the development of HBM in Poland, this issue.

Morris, A.N., Ballentine, K.L., Farmer, E.M., 2012. Learning for and from the field: the experience of being a research interviewer. Resid. Treat. Child. Youth 29, 265-281.

Needham, L.L., Sexton, K., 2000. Assessing children's exposure to hazardous environmental chemicals: an overview of selected research challenges and complexities. J. Expos. Anal. Environ. Epidemiol. 10, 611-629.

Phipatanakul, W., Bailey, A., Hoffman, E.B., Sheehan, W.J., Lane, J.P., Baxi, S., Rao, D., Permaul, P., Gaffin, J.M., Rogers, C.A., Muilenberg, M.L., Gold, D.R., 2011. The school inner-city asthma study: design, methods, and lessons learnt. J. Asthma. 48, 1007-1014.

Post, A., Galanti, M.R., Gilliam, H., 2003. School and family participation in a longitudinal study of tobacco use: some methodological notes. Eur. J. Public Health 13, 75-76.

Schindler, B.K., Esteban, M., Koch, H.M., Castano, A., Koslitz, S., Cañas, A., Casteleyn, L., Kolossa-Gehring, M., Schwedler, G., Schoeters, G., Den Hond, E., Sepai, O., Exley, K., Bloemen, L., Horvat, M., Knudsen, L.E., Joas, A., Joas, R., Biot, P., Aerts, D., Lopez, A., Huetos, O., Katsonouri, A., Maurer-Chronakis, K., Kasparova, L., Vrbík, K., Rudnai, P., Naray, M., Guignard, C., Fischer, M.E, Ligocka, D., Janasik, B., Reis, M.F., Namorado, S., Pop, C., Dumitrascu, I, Halzlova, K., Fabianova, E., Mazej, D., Tratnik, J.S., Berglund, M., Jönsson, B., Lehmann, A., Crettaz, P., Frederiksen, H., Nielsen, F., McGrath, H., Nesbitt, I., De Cremer, K., Vanermen, G., Koppen, G., Wilhelm, M., Becker, K., Angerer, J., 2014. The European COPHES/DEMOCOPHES project: towards transnational comparability and reliability of human biomonitoring results. Int. J. Hyg. Environ. Health 217 (6), 653-661. http://dx.doi.org/ 10.1016/j.ijheh.2013.12.002.

Schoeters, G., Den Hond, E., Colles, A., Loots, I., Morrens, B., Keune, H., Bruckers, L., Nawrot, T., Sioen, I., De Coster, S., Van Larebeke, N., Nelen, V., Van de Mieroop, E., Vrijiens, J., Croes, K., Goeyens, K., Baeyens, W., 2012. Concept of the Flemish human biomonitoring programme. Int. J. Hyg. Environ. Health 215, 102-108.

Schulz, C., Conrad, A., Becker, K., Kolossa-Gehring, M., Seiwert, M., Seifert, B., 2007. Twenty years of the German Environmental Survey (GerES): human biomonitoring-temporal and spatial (West Germany/East Germany) differences in population exposure. Int. J. Hyg. Environ. Health 210, 271-297.

Sepai, O., Collier, C., Van Tongelen, B., Casteleyn, L., 2008. Human biomonitoring data interpretation and ethics; obstacles or surmountable challenges? Environ. Health 7 (Suppl.1), S13. 